\title{
The association between mandibular inferior cortex indices and serum levels of calcium and phosphorus
}

\section{Związek między wskaźnikami części korowej żuchwy oraz stężeniami wapnia i fosforu w surowicy}

\author{
Parisa Soltani $i^{1, A-D, F}$, Mojdeh Mehdizadeh" ${ }^{1, A}, C, E, F$, Mahdis Azimipour ${ }^{2, A}, B, D, F$ \\ 1 Department of Oral and Maxillofacial Radiology, School of Dentistry, Isfahan University of Medical Sciences, I sfahan, Iran \\ ${ }^{2}$ Medical Students' Research Center, School of Medicine, Isfahan University of Medical Sciences, Isfahan, Iran \\ A - research concept and design; $\mathrm{B}$ - collection and/or assembly of data; $\mathrm{C}$ - data analysis and interpretation; \\ $D$ - writing the article; $E$ - critical revision of the article; $F$ - final approval of article
}

\section{Address for correspondence}

Mojdeh Mehdizadeh

E-mail: mehdizadeh@dnt.mui.ac.ir

Funding sources

none declared

Conflict of interest

none declared

\section{Acknowledgements}

The authors would like to thank the authorities of the research council of Isfahan University of Medical Sciences for financially supporting this study (grant No. 394440). The authors also wish to express their gratitude to the personnel of the Department of Oral and Maxillofacial Radiology at the Isfahan School of Dentistry and the clinical laboratory of Alzahra Medical Center for their help.

Received on December 22, 2016

Revised on March 30, 2017

Accepted on May 09, 2017
DOI

10.17219/dmp/71206

Copyright

○ 2017 by Wroclaw Medical University

and Polish Dental Society

This is an article distributed under the terms of the

Creative Commons Attribution Non-Commercial License

(http://creativecommons.org/licenses/by-nc-nd/4.0/)

\begin{abstract}
Background. Mandibular cortical morphology (MCM) and mandibular cortical width (MCW) are 2 indices related to the mandibular inferior cortex in panoramic radiography.

Objectives. The aim of the present study was to evaluate the relationship between serum calcium and phosphorus levels and MCM and MCW in patients over 40 years old at the Department of Oral and Maxillofacial Radiology at Isfahan School of Dentistry.

Material and methods. After the patients signed the consent form, blood specimens were collected and serum calcium and phosphorus levels were determined. Each patient's MCM was determined by observing the mandible distally from the mental foramen on both sides, and was categorized into one of 3 groups based on the degree of erosion. The MCW was measured bilaterally on the radiographs of the mental foramen region.

Results. The examinations found that $63.3 \%$ of the patients had mildly to moderately eroded cortices, and the mean MCW was $4.28 \pm 1.09$. Unlike MCW, which did not differ between the genders, MCM was different in men and women. Also, MCM significantly correlated with age, while MCW did not show this correlation. Neither MCW nor MCM were significantly different between premenopausal and postmenopausal women. Moreover, neither MCW nor MCM were related to serum calcium or phosphorus levels. However, MCW and MCM had a significant negative correlation with each other.

Conclusions. Based on the results of the present study, MCM and MCW were not related to serum calcium or phosphorus levels. However, they had a significant negative correlation with each other. Further studies might clarify any possible relation between mandibular inferior cortex indices and serum calcium and phosphorus levels.
\end{abstract}

Key words: mandible, cortical indices, panoramix radiography, serum, calcium, phosphorus

Słowa kluczowe: żuchwa, wskaźniki korowe, pantomografia, surowica, wapń, fosfor 
The mandibular inferior cortex is one of the anatomical landmarks of panoramic radiography. Mandibular cortical morphology (MCM) and mandibular cortical width $(\mathrm{MCW})$ are two indices related to this landmark. MCM was first classified by Klemetti et al., and is categorized into 3 groups based on the degree of erosion. ${ }^{1} \mathrm{MCW}$ is determinable in a line perpendicular to the tangent of the inferior border of the mandible and intersecting the mental foramen, as described by Taguchi et al. ${ }^{2}$

Several studies have been carried out to investigate possible relationships between mandibular inferior cortex indices and bone metabolism markers. Deguchi et al. concluded that increased serum bone-specific alkaline phosphatase and urinary N-telopeptide crosslinks of type I collagen are significantly associated with mandibular inferior cortex erosion. ${ }^{3}$ In another study by Taguchi et al., no significant relationship was found between MCW and total serum alkaline phosphatase and N-telopeptide crosslinks of type I collagen. ${ }^{4}$ Nevertheless, Vlasiadis et al. reported a significant correlation between serum bone alkaline phosphatase and MCW. ${ }^{5}$ Moreover, a 9-year follow-up study by Kiswanjaya et al. reported that increases in erosion of the mandibular inferior cortex are significantly associated with elevated total serum calcium. ${ }^{6}$

Serum calcium and phosphorus are 2 important markers of bone metabolism..$^{7-9}$ There are several diseases and drugs that change the levels of these minerals. ${ }^{10-12}$ Also, changes in bone turnover appear in individuals over 40 years old, regardless of any pathological condition. ${ }^{13}$ Based on the available literature, there have been few studies investigating possible relationships between these serum markers and mandibular inferior cortex indices in both sexes in various age groups. The aim of the present study was to evaluate the relationship between serum calcium and phosphorus levels and MCM and MCW in patients over 40 years old at the Department of Oral and Maxillofacial Radiology at Isfahan School of Dentistry (Isfahan, Iran).

\section{Material and methods}

\section{The subjects}

This analytic cross-sectional study involved patients over 40 years old who came to the department to have panoramic radiographs taken. Inclusion criteria for the study were: a lack of systemic and metabolic diseases; a lack of congenital disorders; no history of major mandibular surgery or ovariectomy; not taking calcium, phosphorus or vitamin D supplements, anti-acids, lithium, thiazide diuretics, thyroxin or steroids. Patients were excluded if they were unwilling to participate in the study or if their panoramic radiographs contained errors or lacked clarity in the desired region. All the participants signed a consent form prior to enrollment in the study. The Isfahan Regional Bioethics Committee approved the study (permit number 394440).

\section{Data collection}

The patients' demographic information was recorded, including age, sex, and the mentrual status of the females (premenopausal or postmenopausal). All the panoramic radiographs were taken using the Proline ${ }^{\circledR} \mathrm{XC}$ digital panoramic X-ray unit (Planmeca, Helsinki, Finland), with the patient's head positioned in the device with the midsagittal plane perpendicular and Frankfurt plane parallel to the floor. Blood specimens were then collected from each participant and serum calcium and phosphorus levels were determined.

The panoramic radiographs were displayed on a monitor (Flatron ${ }^{\circledR}$, LG Electronics, Seoul, South Korea) using the associated software. MCM was determined by observing the mandible distally from the mental foramen on both sides and categorized in accordance with Klemetti et al. ${ }^{1}$ (Fig. 1):

1. Class 1 (normal cortex): The endosteal margin of the cortex is even and sharp on both sides.

2. Class 2 (mildly to moderately eroded cortex): The endosteal margin has semilunar defects (lacunar resorption) or there are cortical residues on one or both sides.

3. Class 3 (severely eroded cortex): There are heavy endosteal cortical residues and the cortical layer is clearly porous on one or both sides.

The MCW was measured bilaterally on the radiographs in the mental foramen region. A line tangential to the inferior border of the mandible was drawn. A line perpendicular to this tangent and intersecting the mental foramen was drawn, and the MCW was measured along this line (Fig. 2). The mean values of the MCW on both sides was used for the statistical analysis. ${ }^{2}$ The determination of the MCM and MCW for all the radiographs was done by 2 observers: an oral and maxillofacial radiologist
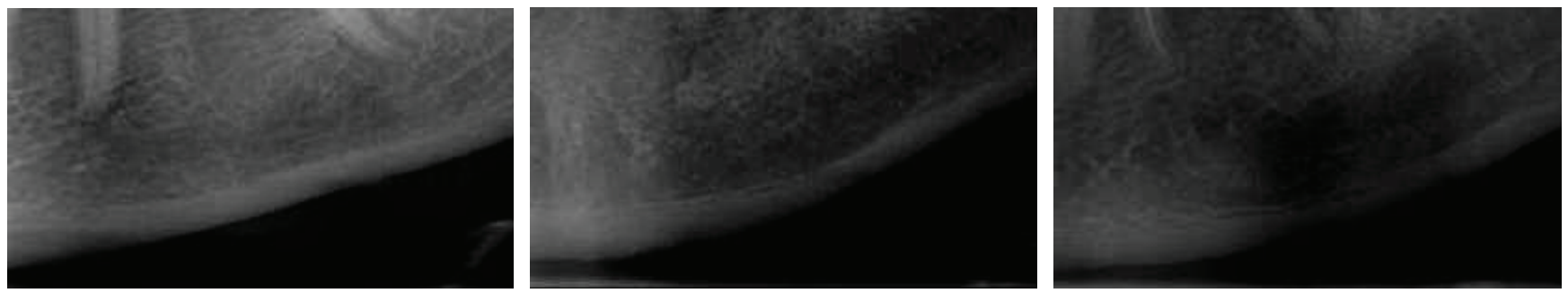

Fig. 1. MCM classifications: a) class 1, b) class 2, and c) class 3 
and a trained dental student. Inter-observer agreement was reported to be high for both MCM (kappa $=0.963$, $\mathrm{p}<0.001)$ and MCW $(\mathrm{ICC}=0.963, \mathrm{p}<0.001)$. Therefore, the measurements of the first observer were recorded for MCM, and the mean values obtained by the two observers were recorded for $\mathrm{MCW}$.

\section{Statistical analysis}

The data were analyzed using IBM SPSS Statistics v. 22 software (IBM Corp., Armonk, USA). Pearson and Spearman correlation coefficients, the Mann-Whitney U test and Student's t-test were used for the statistical analysis. The level of significance was set as $\alpha=0.05$.

\section{Results}

Out of the 90 participants in the study, 55 (61.1\%) were female and $35(38.9 \%)$ were male. Among the female patients, 30 (54.5\% of the females and $33.3 \%$ of all the patients) were premenopausal and 25 (45.5\% of the females and $27.8 \%$ of all the patients) were postmenopausal. The age of the patients ranged from 40.08 to 70.50 $($ mean $=51.26 \pm 7.55)$.

Most of the patients (63.3\%) had mildly to moderately eroded cortices (MCM Class 2), while $23.3 \%$ of them had severely eroded cortices (MCM Class 3 ) and $13.3 \%$ had normal ones (MCM Class 1). MCW ranged between $0.85 \mathrm{~mm}$ and $8.02 \mathrm{~mm}$, with a mean value of $4.28 \pm 1.09 \mathrm{~mm}$.

The statistical analysis revealed that MCW was not significantly different between men and women ( $\mathrm{p}=0.666$ ). However, MCM was significantly different between men and women $(\mathrm{p}=0.05)$. Neither MCW ( $\mathrm{p}=0.645)$ nor MCM ( $p=0.75)$ were significantly different between

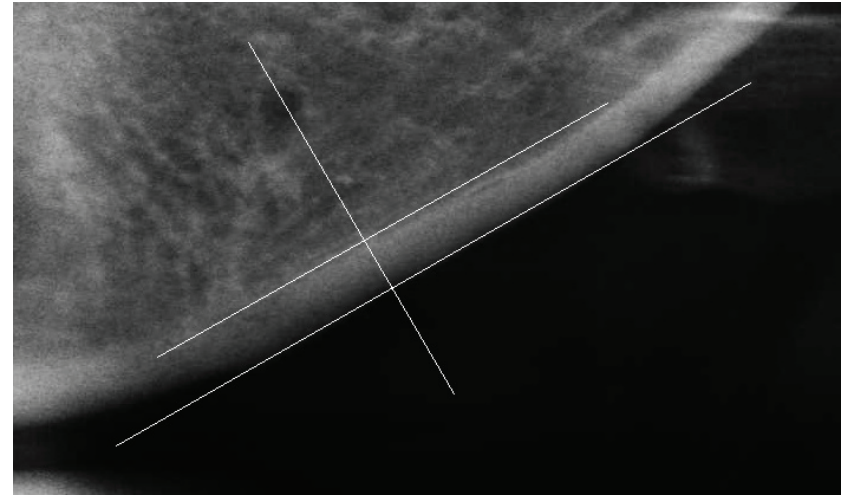

Fig. 2. Determination of MCW

premenopausal and postmenopausal women. MCM had a positive correlation with age $(r=0.280, p=0.008)$, while MCW was not significantly associated with age $(r=0.019$, $\mathrm{p}=0.862$ ).

MCM was not significantly correlated with calcium $(\mathrm{r}=-0.131, \mathrm{p}=0.219)$ or with phosphorus $(\mathrm{r}=-0.28$, $\mathrm{p}=793)$. Similarly, $\mathrm{MCW}$ did not have any significant relation to calcium $(\mathrm{r}=0.122, \mathrm{p}=0.253)$ or phosphorus $(\mathrm{r}=-0.166, \mathrm{p}=0.118)$. MCW and MCM had a statistically significant negative correlation $(\mathrm{r}=-0.346, \mathrm{p}<0.001)$ : Higher MCM classification levels were associated with lower MCW. Tables 1 and 2 present the characteristics of the study subjects based on MCM classification and MCW quartiles, respectively.

\section{Discussion}

This study found that MCM classification differed significantly between men and women. MCM also significantly correlated with age, while MCW did not.

Table 1. Characteristics of the study subjects based on MCM classification

\begin{tabular}{|c|c|c|c|c|}
\hline Patient groups & MCM & Class 1 & Class 2 & Class 3 \\
\hline \multirow{5}{*}{ Premenopausal females } & number of subjects & 7 & 20 & 3 \\
\hline & mean age (years) & 47.88 & 47.61 & 46.05 \\
\hline & calcium (mg/dL) & 9.64 & 9.39 & 8.50 \\
\hline & phosphorus (mg/dL) & 3.11 & 2.93 & 3.17 \\
\hline & mean MCW (mm) & 4.73 & 4.26 & 3.46 \\
\hline \multirow{5}{*}{ Postmenopausal females } & number of subjects & 3 & 15 & 7 \\
\hline & mean age (years) & 50.14 & 54.14 & 57.86 \\
\hline & calcium (mg/dL) & 9.40 & 9.88 & 9.67 \\
\hline & phosphorus (mg/dL) & 3.20 & 2.97 & 3.20 \\
\hline & mean MCW (mm) & 3.92 & 4.50 & 3.58 \\
\hline \multirow{5}{*}{ Males } & number of subjects & 2 & 22 & 11 \\
\hline & mean age (years) & 45.71 & 50.75 & 55.69 \\
\hline & calcium (mg/dL) & 10.05 & 9.06 & 9.30 \\
\hline & phosphorus (mg/dL) & 2.65 & 2.76 & 2.75 \\
\hline & mean MCW (mm) & 6.39 & 4.60 & 3.45 \\
\hline
\end{tabular}


Table 2. Characteristics of the study subjects based on MCW quartiles

\begin{tabular}{|c|c|c|c|c|c|}
\hline Patient groups & MCM & $<25 \%$ & $25-50 \%$ & $50-75 \%$ & $>75 \%$ \\
\hline \multirow{4}{*}{ Premenopausal females } & number of subjects & 6 & 9 & 11 & 4 \\
\hline & mean age (years) & 44.92 & 46.90 & 50.42 & 44.83 \\
\hline & calcium (mg/dL) & 9.27 & 9.23 & 9.54 & 9.32 \\
\hline & phosphorus (mg/dL) & 3.50 & 2.78 & 2.94 & 2.90 \\
\hline \multirow{4}{*}{ Postmenopausal females } & number of subjects & 6 & 9 & 5 & 6 \\
\hline & mean age (years) & 55.55 & 51.22 & 56.68 & 56.82 \\
\hline & calcium (mg/dL) & 9.58 & 9.82 & 9.84 & 9.80 \\
\hline & phosphorus (mg/dL) & 3.12 & 2.92 & 3.34 & 2.97 \\
\hline \multirow{4}{*}{ Males } & number of subjects & 10 & 7 & 7 & 11 \\
\hline & mean age (years) & 52.26 & 50.51 & 50.28 & 53.84 \\
\hline & calcium (mg/dL) & 9.00 & 9.47 & 9.13 & 9.24 \\
\hline & phosphorus (mg/dL) & 2.87 & 2.69 & 2.60 & 2.79 \\
\hline
\end{tabular}

Moreover, neither MCM nor MCW were related to serum calcium or phosphorus levels; however, they had a significant negative correlation with each other.

In this study MCW did not show any significant difference between the genders; the mean MCW was 4.24 and 4.34 in women and men, respectively. In a study by Mirbeigi et al. in an Iranian population, the mean MCW values were 3.72 in women and 4.74 in men, which was a statistically significantly difference. ${ }^{14}$ According to Vlasiadis et al., the mean MCW in a Greek female population was $4.57 \pm 1.03 .^{15}$ These discrepancies might have resulted from variable magnification factors for different radiographic devices, as well as ethnic differences. A study performed by Dutra et al. suggested that mean MCW values are higher in men, especially in old age; they observed a significant difference in the mean values of MCW between the genders in patients older than 75 years. ${ }^{16}$ In the present study none of the patients were in this age range, and this may be the reason that no gender difference was noted. However, a study of Polish patients aged 20 to 95 years by Kalinowski and Różyło-Kalinowska concluded that MCW is higher in males in all age groups. ${ }^{17}$ The difference between the findings may be attributed to the smaller sample size in the present study compared to their study.

In the present study, class $3 \mathrm{MCM}$ was more frequent in men and postmenopausal women than premenopausal women, while class $1 \mathrm{MCM}$ was more frequently observed in premenopausal women; however, these difference did not reach the level of statistical significance Generally, mild to severe erosion of the mandibular cortex was significantly more common in men than in women. As far as the authors know, no previous study of MCM has included men, premenopausal women and postmenopausal women and differentiated the findings in this respect. A study by Gulsahi et al. in a Turkish population failed to show any significant relationship between the genders regarding MCM. ${ }^{18}$ Other studies concluded that
MCM is significantly different between men and women, and that class 3 is higher in women than in men. ${ }^{19,20}$ The differences between the findings of these studies may be attributed to different sample sizes and different ages of the participants.

In this study MCW was not affected by age. In their study on a group of females, Ledgerton et al. reported that MCW is negatively correlated with age, especially between the ages of 55 to 74 years, which is older than the mean age of the participants in the present study. ${ }^{21}$

MCM was significantly correlated with age in the present study. This finding is consistent with a study by Vlasiadis et al. in which MCM class 2 and class 3 are associated with increased age. ${ }^{15}$ Similar age-related trends have been reported in studies by Gulsahi et al., ${ }^{18}$ Ledgerton et al., ${ }^{21}$ and Knezović Zlatarić et al. ${ }^{22}$

In this study MCM and MCW were found to have a significant negative correlation with each other. This finding is in agreement with a study by Vlasiadis et al. in which mild to severe cortical erosion was associated with decreased MCW. ${ }^{15}$ Moreover, this negative correlation was also observed in studies by Govindraju et al. ${ }^{23}$ on an Indian population and by Khatoonabad et al. on an Iranian population. ${ }^{24}$

In the present study neither MCM nor MCW were significantly correlated with serum calcium or phosphorus levels. Similar findings were reported in a study by Johari Khatoonabad et al. ${ }^{24}$ However, a 9-year follow-up study on 70-year-old individuals by Kiswanjaya et al. concluded that an increase in erosion of the mandibular inferior cortex was associated with an elevated serum calcium level only in women. ${ }^{6}$ In the present study, the mean values of serum calcium and phosphorus (presented in Table 1) were all within the normal range. It seems that at least in middle-aged patients, factors associated with the regulation of serum minerals maintain calcium and phosphorus within normal limits even when bone is undergoing resorption. However, in older patients these mechanisms 
may fail to precisely regulate serum calcium and phosphorus levels following remodeling and resorption changes in bone. This could explain why significant correlations were not observed between mandibular inferior cortex indices and serum levels of calcium and phosphorus. Studies performed on older patient populations may help to clarify any association.

One of the limitations of the present study was that it omitted to take into account the number of months past menopause in postmenopausal women, as many of the female participants did not give clear information regarding the exact time of menopause. For further investigations, follow-up studies are suggested to monitor changes in mandibular inferior cortex indices and bone turnover markers over a longer period of time.

\section{Conclusions}

The results of the present study indicated that MCM and MCW were not related to serum calcium or phosphorus levels. However, they had a significant negative correlation with each other. While MCW did not show any correlation with age or gender, MCM was significantly associated with both age and gender. Further studies might clarify any possible relation between mandibular inferior cortex indices and serum calcium and phosphorus levels.

\section{References}

1. Klemetti E, Kolmakow S. Morphology of the mandibular cortex on panoramic radiographs as an indicator of bone quality. Dentomaxillofacial Radiol. 1997;26:22-25.

2. Taguchi A, Suei Y, Ohtsuka M, Otani K, Tanimoto K, Ohtaki M. Usefulness of panoramic radiography in the diagnosis of postmenopausal osteoporosis in women. Width and morphology of inferior cortex of the mandible. Dentomaxillofacial Radiol. 1996;25:263-267.

3. Deguchi T, Yoshihara A, Hanada N, Miyazaki H. Relationship between mandibular inferior cortex and general bone metabolism in older adults. Osteoporos Int. 2008;19:935-940.

4. Taguchi A, Sanada M, Krall E, et al. Relationship between dental panoramic radiographic findings and biochemical markers of bone turnover. J Bone Miner Res. 2003;18:1689-1694.

5. Vlasiadis KZ, Damilakis J, Velegrakis GA, et al. Relationship between $B M D$, dental panoramic radiographic findings and biochemical markers of bone turnover in diagnosis of osteoporosis. Maturitas. 2008;59:226-233.

6. Kiswanjaya B, Yoshihara A, Miyazaki H. Mandibular inferior cortex erosion as a sign of elevated total serum calcium in elderly people: A 9-year follow-up study. Dentomaxillofacial Radiol. 2014;43:20130341.

7. Moe SM. Disorders involving calcium, phosphorus, and magnesium. Prim Care. 2008;35:215-237.

8. Charoenphandhu N. Physical activity and exercise affect intestinal calcium absorption: A perspective review. J Sports Sci Technol. 2007;7:171-181.

9. Hamed SA, Moussa EM, Youssef AH, ElHameed MAA, NasrEldin E. Bone status in patients with epilepsy: relationship to markers of bone remodeling. Front Neurol. 2014;5:142.

10. Rubin MR, Lee KH, McMahon DJ, Silverberg SJ. Raloxifene lowers serum calcium and markers of bone turnover in postmenopausa women with primary hyperparathyroidism. J Clin Endocrinol Metab. 2003;88:1174-1178.
11. Gutman AB, Tyson TL, Gutman EB. Serum calcium, inorganic phosphorus and phosphatase activity: In hyperparathyroidism, Paget's disease, multiple myeloma and neoplastic disease of the bones. Arch Intern Med. 1936;57:379-413.

12. Raggi $P$, Boulay A, Chasan-Taber S. Cardiac calcification in adult hemodialysis patients: A link between end-stage renal disease and cardiovascular disease? J Am Coll Cardiol. 2002;39:695-701.

13. White SC, Pharoah MJ. Oral radiology: Principles and interpretation. Elsevier Health Sciences. 2014.

14. Mirbeigi S, Khojastepour L, Ezoddini F. Correlation between mandibular radiomorphometric parameters and gonial angle size in Iranian adults. J Dentomaxillofacial Radiol Pathol Surg. 2014;3:28-34.

15. Vlasiadis KZ, Skouteris CA, Velegrakis GA. Mandibular radiomorphometric measurements as indicators of possible osteoporosis in postmenopausal women. Maturitas. 2007;58:226-235.

16. Dutra V, Yang J, Devlin H, Susin C. Radiomorphometric indices and their relation to gender, age, and dental status. Oral Surg Oral Med Oral Pathol Oral Radiol Endod. 2005;99:479-484.

17. Kalinowski P, Różyło-Kalinowska I. Mandibular inferior cortex width may serve as a prognostic osteoporosis index in Polish patients. Folia Morphol. 2011;70:272-281.

18. Gulsahi A, Yüzügüllü $B$, İmirzalıoğlu P, Genç Y. Assessment of panoramic radiomorphometric indices in Turkish patients of different age groups, gender and dental status. Dentomaxillofacial Radiol. 2008;37:288-292.

19. Uysal S, Cağirankaya B, Hatipoğlu MG. Do gender and torus mandibularis affect mandibular cortical index? A cross-sectional study. Head Face Med. 2007;3:37.

20. Hastar E, Yilmaz HH, Orhan H. Evaluation of mental index, mandibular cortical index and panoramic mandibular index on dental panoramic radiographs in the elderly. Eur J Dent. 2011;5:60-67.

21. Ledgerton D, Horner $\mathrm{K}$, Devlin $\mathrm{H}$, Worthington $\mathrm{H}$. Radiomorphometric indices of the mandible in a British female population. Dentomaxillofacial Radiol. 1999;28:173-181.

22. Knezović Zlatarić D, Čelebić A, Lazić B, et al. Influence of age and gender on radiomorphometric indices of the mandible in removable denture wearers. Coll Antropol. 2002;26:259-266.

23. Govindraju P, Chandra P. Radiomorphometric indices of the mandible - an indicator of osteoporosis. J Clin Diagn Res. 2014;8:195.

24. Johari Khatoonabad M, Aghamohammadzade N, Taghilu H, Esmaeili F, Jabbari Khamnei $H$. Relationship among panoramic radiography findings, biochemical markers of bone turnover and hip BMD in the diagnosis of postmenopausal osteoporosis. Iran J Radiol. 2011;8:23-28. 